\title{
Promotion of a primary healthcare philosophy in a community-based nursing education programme from the students' perspective
}

\author{
I Ndateba, ${ }^{1} \mathrm{MN}$; F Mtshali, ${ }^{1} \mathrm{PhD} ; \mathrm{S} \mathrm{Z}$ Mthembu, ${ }^{2} \mathrm{PhD}$ \\ ${ }^{1}$ School of Nursing and Public Health, University of KwaZulu-Natal, Durban, South Africa \\ ${ }^{2}$ KwaZulu-Natal College of Nursing, Durban, South Africa
}

Corresponding author: S Z Mthembu (sindizama@gmail.com)

Background. Community-based education (CBE) serves as a primordial instrument in the implementation of primary healthcare (PHC). Learning experiences in community-based settings provide students with learning opportunities, as they are actively engaged in PHC-associated activities in under-resourced communities. Many nursing schools in higher education integrated and implemented a CBE programme with an end-goal of becoming healthcare practitioners who are responsive to the needs of the community.

Objectives. To establish how PHC philosophy is promoted through a community-based nursing education programme.

Methods. The study was non-experimental and cross-sectional with a quantitative approach and was done at a selected higher education institution in KwaZulu-Natal, South Africa. A total of 118 participants were selected using the non-probability convenience sampling technique. A self-report questionnaire was distributed to the participants; 91 questionnaires were completed and returned - a response rate of $73.3 \%$. Ethical clearance was obtained from the University of KwaZulu-Natal Ethics Review Committee. Participation was voluntary, informed consent was obtained, and other ethical principles were respected. Data were analysed with the Statistical Package for Social Sciences (SPSS). Descriptive and analytical analysis was used to analyse the data.

Results. The participants reported exposure to community-based learning from the first until the fourth year of their study programme. Participants (69.9\%) indicated that their learning activities had involved members of the community. The community-based learning projects, which mostly promoted a PHC philosophy, included prevention of illness, injuries and social problems (90.1\%), health promotion (89\%) and engaging communities in community-based learning activities to promote their self-reliance and self-determination (76.9\%).

Conclusion. Findings revealed that the community-based learning experiences of students promoted a PHC philosophy and that underprivileged community settings provided a rich learning environment.

Afr J Health Professions Educ 2015;7(2):190-193. DOI:10.7196/AJHPE.399

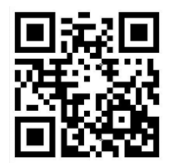

The traditional teaching approach has been criticised for not equipping health professionals with the necessary knowledge and skills to work in rural, remote and under-resourced communities. $^{[1,2]}$ The conventional approach focuses on hospital-based, curative-focused teaching, which relies on sophisticated technology. Furthermore, upon graduation, many nurses are reluctant to work in rural, underprivileged areas, where resources are scant and the focus is on healthcare and prevention. ${ }^{[2]}$ This instructional approach hinders the equal distribution of health professionals in South Africa (SA) and therefore the quality of services provided to its citizens. This, in turn, impedes the promotion of primary healthcare (PHC).

The World Health Organization (WHO) defines PHC as 'essential healthcare based on practical scientifically sound and socially sound acceptable method and technology, universally accessible to all in the community through their full participation; at an affordable cost, and geared toward self-reliance and self-determination. ${ }^{\left.{ }^{2}\right]} \mathrm{PHC}$ is therefore an approach to healthcare that promotes the attainment by all people of a level of health that will permit them to live socially and economically productive lives. Healthcare is essential, practical, socially and scientifically sound (evidence based), ethical, accessible, equitable, affordable, and accountable to the community. Furthermore, $\mathrm{PHC}$ is more than primary medical or curative care or a package of low-cost medical interventions for the poor and marginalised.

To address these challenges, the WHO, International Council of Nurses (ICN) and South African Nursing Council (SANC) recommended the implementation of a community-based education (CBE) programme as part of the teaching curriculum in the training of nurses. ${ }^{[2,4-6]} \mathrm{CBE}$ refers to learning activities that take place in a particular setting, i.e. the community setting. ${ }^{[7]}$ Students are allocated to different communities (urban, peri-urban and rural or semi-rural) to undertake activities relevant to community health needs and that address community health-related needs. CBE may contribute to solve the inequity in service delivery by producing healthcare professionals who are willing and able to work in underserved areas, particularly rural communities. ${ }^{[8,9]}$ CBE also offers opportunities for students to learn in situations similar to those in which they might work later in their professional lives. It may equip students with transferable core competencies that they would not learn otherwise, such as leadership skills, the ability to work in teams, and the capability to interact with the community.

The South African Department of Education (DoE) and the Council on Higher Education (CHE) endorse the implementation of $\mathrm{CBE}$ as a responsive educational method. ${ }^{[10]}$ Furthermore, the Department of Health (DoH) (SA), in the 1997 White Paper on the Transformation of the Health System, highlighted that in order to align nursing education with PHC the curriculum should be based on community needs and linked to PHC. ${ }^{[1]}$ Gumbi and Muller ${ }^{[12]}$ and Mekwa ${ }^{[6]}$ emphasised that the curriculum of health professionals should be linked to PHC.

Mekwa $^{[6]}$ states that CBE is a tool to foster PHC, as it affords students the opportunity to learn by providing services to under-resourced communities. Various higher education institutions for health professionals, including 
nursing institutions, have responded positively by allowing students to engage in PHC-associated activities. ${ }^{[13]}$ However, little is known about whether this programme promotes the $\mathrm{PHC}$ approach. This article presents the findings of a study aimed at exploring whether $\mathrm{CBE}$ activities promote PHC.

\section{Methods}

Following a quantitative approach and a non-experimental, explorative, descriptive design, a cross-sectional survey was used to explore students' perspectives of whether CBE promotes PHC. Non-probability convenience sampling was used to invite 118 students to participate in the study. They included second-, third- and fourth-year students who were studying for a Bachelor in Nursing degree at a university-based College of Nursing in KwaZulu-Natal, SA. The students were selected to participate, as they had been exposed to the CBE programme. First-year students were excluded because of the limited exposure to community-based learning at first-year level. Permission to conduct the study was obtained from the University of KwaZulu-Natal Ethics Review Committee. Participation was voluntary and informed consent was obtained from participants after the study had been thoroughly explained to them. Questionnaires were distributed to the participants; 91 were completed and returned - a response rate of $73.3 \%$.

Experts in CBE and PHC at the University of KwaZulu-Natal, and the related literature and studies, facilitated the measurement of validity of the instrument. To test the consistency of the measurements, a pilot study was conducted with 6 participants, who were not included in the final analysis. Descriptive and analytical statistics were used in the data analysis. Cronbach's $\alpha$ was 0.851 and a $p$-value $\leq 0.5$ was considered statistically significant.

\section{Results}

\section{Research setting}

The selection of clinical training sites in the community is considered an important aspect of CBE for an effective process of knowledge construction. Students are placed in urban, suburban and informal settlements and semirural communities. The communities around the university are used extensively as a learning environment to give students an opportunity to understand the capacities and initiatives of the communities they serve. Nearby PHC clinics, schools and other community centres are used. These communities all provide rich information with regard to the raw content material and a variety of health problems that could be used as a frame of reference for CBE.
Students are involved in CBE from their first to their fourth year of study and exposed to learning in various community settings, including PHC facilities and other community centres. Their communitylearning activities were carried out in old-age homes (82.4\%), crèches (24.4\%), general hospitals (94\%), PHC clinics (34.4\%) and psychiatric settings (36.7\%). Participants indicated that their CBE activities promoting PHC had involved community members from different sectors. The study revealed that $69.9 \%$ of respondents indicated that their community-learning activities had involved members of the community and $85.7 \%$ had participated in the implementation of community projects. It was found that these activities involved school teachers $(95.6 \%)$, local leaders $(91.2 \%)$, church leaders (44\%), youth leaders $(60.4 \%)$, community health workers $(89 \%)$, nurses $(87.95)$ and community members $(94.3 \%)$.

The student learning experiences also reflect identification of community health problems.

The results of this study showed that $97.8 \%(n=89)$ of students had participated in family assessment, while $100 \%(n=91)$ had conducted epidemiological studies. Additionally, the findings indicated that $100 \%$ ( $n=91)$ had carried out community assessment to identify community health needs, and $95.6 \%(n=81)$ had validated needs from the community to identify health need priorities.

Eighty-nine per cent of participants had been involved in CBE activities that focused on health promotion, $90.1 \%$ on prevention of illness, injuries and social problems, $52.7 \%$ on treatment of common illnesses and injuries at home, $45.1 \%$ on rehabilitative care, which was associated with learning in an informal settlement, and $76.9 \%$ on promoting community self-reliance and self-determination.

The focus of CBE projects can be seen in Table 1 .

The study indicated that students were exposed to many aspects of PHC in various learning environments, such as classrooms, communities, $\mathrm{PHC}$ facilities and hospitals. In these CBE environments, $71.4 \%$ of participants learnt about health education with regard to preventing diseases and promoting health, $52.7 \%$ were exposed to learning about oral rehydration for children and $57.1 \%$ learnt about breastfeeding. The study also revealed that $62.6 \%$ had an opportunity to learn about family planning for males and females and $70.3 \%$ learnt about prevention of malnutrition in children. Furthermore, $58.2 \%$ could familiarise themselves with first-aid measures at home, $52.7 \%$ with monitoring the growth of children and $60.4 \%$ with immunisation of babies.

\section{Table 1. Focus of community-based learning projects}

\begin{tabular}{|c|c|c|c|}
\hline Focus of community-based project & Yes, $n(\%)$ & No, $n(\%)$ & Total, $\boldsymbol{n}(\%)$ \\
\hline $\begin{array}{l}\text { Promotion of health (health education on nutrition, sexuality, breastfeeding, environmental health, waste disposal, } \\
\text { safe and clean water) }\end{array}$ & $81(89)$ & $10(11)$ & $91(100)$ \\
\hline $\begin{array}{l}\text { Prevention of illness, injuries and social problems (e.g. immunisations, family planning, health education } \\
\text { on prevention of sexually transmitted infections, chronic illnesses (e.g. hypertension) and teenage pregnancy) }\end{array}$ & $82(90.1)$ & $9(9.9)$ & $91(100)$ \\
\hline $\begin{array}{l}\text { Treatment of common illnesses and injuries at home (e.g. treatment of lice, diarrhoea and vomiting, flu, } \\
\text { minor burn injuries) }\end{array}$ & $48(52.7)$ & $43(47.3)$ & $91(100)$ \\
\hline $\begin{array}{l}\text { Rehabilitative care (e.g. home management of patients with deformities, elderly patients with chronic illnesses, } \\
\text { and mentally ill clients in the community) }\end{array}$ & $41(45.1)$ & $50(54.9)$ & $91(100)$ \\
\hline $\begin{array}{l}\text { Promoting community self-reliance and self-determination (e.g. identifying, accessing and using available resources } \\
\text { in the community to address health-related issues) }\end{array}$ & $70(76.9)$ & $21(23.1)$ & $91(100)$ \\
\hline
\end{tabular}


The results revealed that $\mathrm{CBE}$ had given $70.3 \%$ of the participants the opportunity to learn about community involvement in community-based projects, $38.5 \%$ had become involved in advocating for vulnerable people and $50.5 \%$ learnt about educating the community about waste disposal. The study showed that $56.7 \%$ learnt about ways to keep water clean if there is no safe water supply and $51.6 \%$ about caring for terminally ill patients at home. Moreover, $57.1 \%$ acquired knowledge about women empowerment and 59.3\% about collaborating with other sectors to address health issues in the community. The findings indicated that $94.3 \%$ of the participants had been involved in fundraising for community projects, while $80.2 \%$ had participated in helping the community to take responsibility for their health and mobilising resources for promoting community self-determination.

The community-based learning projects that participants were exposed to were associated with the promotion of health; prevention of illnesses, injuries and social problems; home treatment of common illnesses and injuries; rehabilitative care and community self-reliance and self-determination.

\section{Discussion}

CBE is an approach to teaching and learning that exposes students to community nursing from an early stage of the course until their fourth year. This takes place in a variety of real-world settings, including the community and specialty learning environments as stated by Mthembu and Mtshali. ${ }^{[7]}$ Such early exposure to a community setting aims to familiarise students with $\mathrm{PHC}$ principles to equip them with the culture of $\mathrm{PHC}$ practice about health promotion and disease prevention. ${ }^{[5,14]}$

The continuity of community learning is crucial as it helps students to maintain a spirit of community practice, while striving to become competent nurses. Ongoing experience of working in PHC settings and providing healthcare services to under-served communities not only reinforces internalisation of health promotion and illness prevention throughout the educational programme, but also makes healthcare services more accessible to the community.

The current study showed that $97.8 \%$ ( $n=89$ ) of students had participated in family assessment, while $100 \%$ ( $n=91$ ) had conducted epidemiological studies. Additionally, the findings indicated that all students $(n=91)$ had carried out community assessment to identify community health needs, and $95.6 \%(n=81)$ had validated needs from the community to identify health need priorities. These results are congruent with the findings of various other studies ${ }^{[7,15-17]}$ that students who engaged in CBE learnt to identify community healthcare needs and implement health interventions to address health problems. This enables both students and community members to identify real issues in the community and the available resources. ${ }^{[7]}$ As a result of the experience they gain through community studies, students learn to understand how cultural, socioeconomic and political factors are interrelated and how these factors determine the health status of the population. ${ }^{[1,18]}$ This enables them, as PHC practitioners, to implement the necessary measures to affect these determinants of health.

This process of identifying community health problems and validating needs is in line with the PHC philosophy where community members participate in the identification of their needs and resources. ${ }^{[5]}$ Findings showed that the principle of community participation was reflected in this CBE programme, where $70.3 \%$ ( $n=64)$ of respondents had been exposed to learning about community involvement and $51.6 \%(n=47)$ had covered it in the classroom learning environment.

Furthermore, $69.9 \%$ of respondents indicated that their communitylearning activities had involved members of the community and $85.7 \%$ had participated in the implementation of community projects. This embraces the PHC principle that community members should be involved in the planning, implementation, monitoring and evaluation of communitybased projects aimed at addressing their health needs. ${ }^{[19]}$ The findings are also consistent with recommendations from the $\mathrm{WHO}^{\left[{ }^{[5]}\right.}$ which state that community members should be involved in students' educational experiences, not only to provide support to foster learning, but also to ensure that community needs are satisfied.

The success of CBE depends on community participation in the educational process. The community helps students by identifying health problems in the community, which forms the curriculum content. In return, they benefit from the services provided by students. ${ }^{[7,14]}$ During the learning experience, students and community members jointly plan and implement community-based learning projects, which enhances closeness between both groups, a sense of belonging for students, ownership of the interventions implemented, and their acceptability for the community. ${ }^{[20]}$ This achieves the main objective, i.e. improving the health of the community being served.

The findings indicated that $94.3 \%$ of the participants had been involved in fundraising for community projects, while $80.2 \%$ had participated in assisting the community to take responsibility for their health. Students were also involved in mobilising resources for promoting community self-determination - a principle of PHC. The role of PHC practitioners involves helping the community through collaboration, partnerships with other sector teams and advocacy to assume control of their lives. According to Mtshali, ${ }^{[1]} \mathrm{CBE}$ prepares nursing students to fulfil this role, which aims to improve the health of the population through health promotion, disease prevention, and self-reliance and -determination of community members with regard to their health. According to the WHO and Health and Welfare Canada, ${ }^{[21]}$ health is considered as a resource for community development.

The community-based projects of $89 \%$ of respondents focused on PHC components of health promotion. Also, $90.1 \%$ of community-based projects focused on prevention of illness, injuries and social problems, and $45.1 \%$ of respondents conducted community-based projects focused on rehabilitative care of patients with deformities, elderly patients with chronic illnesses and mentally ill clients.

This study revealed that $52.7 \%$ of respondents conducted communitybased projects on the treatment of common illnesses and injuries at home, such as treatment of lice, diarrhoea and vomiting, flu and minor burn injuries, and $76.9 \%$ carried out projects on promoting community self-reliance and -determination, such as identifying, accessing and using available resources in the community to address health-related issues.

The findings are congruent with the results of studies conducted elsewhere, ${ }^{[15,22-24]}$ which showed that nursing students in CBE implemented various health-promotion and disease-prevention programmes to vulnerable groups, targeting diabetes, heart diseases, safe sexual behaviours and prevention of infectious diseases, such as sexually transmitted infections, tuberculosis, and HIV and AIDS. The health-promotion and diseaseprevention programmes incorporated immunisation, oral health, infant feeding, hygiene products, transmission of germs, preparation for cold weather, healthy eating, women's health issues and assessment of blood pressure for adults. These studies revealed that CBE has a positive impact on the lives of target groups, while enabling the learners to become socially 
responsible and respond to the needs of the community, especially those who are underserved and vulnerable..$^{[5,25,26]}$

The community-based nursing education programme is in line with recommendations of the $\mathrm{DoH},{ }^{[11]} \mathrm{DoE},{ }^{[10]} \mathrm{SANC}$ and various other international organisations. These institutions stipulate that the education of healthcare professionals should be responsive to community needs in achieving learning objectives by actively involving students in learning experiences that bring about change in the community. ${ }^{[6,7,10,11,27]}$ The literature maintains that this approach provides comprehensive learning experiences that focus on health promotion, illness prevention, treatment, and rehabilitation, and that it promotes self-reliance and -determination of the community. ${ }^{[1,2]}$ Education is therefore linked to PHC, making PHC philosophy a driving force in healthcare in the world and in SA in particular. ${ }^{[1,3,5,7,13,28]}$

Students' community-based learning projects focused on providing healthcare services according to the needs of the community. As a social justice teaching approach, ${ }^{[29]}$ this enhanced accessibility of the health service to underserved areas, thus promoting equity in healthcare services provision, which is in accordance with the social justice orientation of the PHC philosophy. One of the principles of $\mathrm{PHC}$ is equity in healthcare provision, with the ultimate goal of changing the lives of the population being served. Equity in healthcare delivery has been reiterated in the PHC Declaration of Alma-Ata. ${ }^{[3]}$

The findings are in line with the recommendations of the Lancet report of 2010, stipulating that the curriculum of health professionals should equip them with competencies to practise at community level, where they provide PHC services focusing mainly on health promotion and prevention of diseases. It further stipulates that health professionals should learn to work in teams, as maintenance and restoration of health depend on multiskilled professionals. ${ }^{[30]}$ This study shows that the educational experiences of students in the community incorporate the essential elements of PHC and are consistent with the aims of the Alma-Ata declaration, ${ }^{[3]}$ i.e. to address the health problems of a community by making healthcare services accessible to them and by promotive, preventive, curative and rehabilitative healthcare education and services to prevent diseases and improve health.

Our findings are congruent with the results of the study conducted in SA by Mtshali, ${ }^{[1]}$ who found that learning experiences in community-based nursing education exposed students to a number of strategies aimed at promoting and improving the health status of the population, especially those from underserved and poor groups. The strategies included growth monitoring, oral rehydration, breastfeeding, immunisation, female literacy as women empowerment, family planning, food supplementation to prevent malnutrition, and first aid at home, also known as the GOBI-FFFF strategy by the United Nations Children's Fund (UNICEF). ${ }^{[31]}$

The results of this study showed that community-based learning exposes nursing students to educational experiences that prepare them to fulfil the roles of health promoters, health educators, community and vulnerable group advocators, promoters of community self-reliance and -determination, and members of interdisciplinary teams working together to improve the health of individuals and groups, which according to Keleher et al ${ }^{[32]}$ are the roles of nurses in PHC settings. The findings revealed that community-based learning activities enhance and promote PHC.

\section{Conclusion}

Community-based nursing education as an educational approach provides students with an opportunity to learn and provide services to communities.
The findings show that the students involved community members in their community-based service-learning experience. Students engaged in CBE projects that focused on health promotion, prevention of illnesses, injuries and social problems, treatment of minor illnesses, rehabilitative care and promotion of community self-reliance and -determination. These projects and other learning experiences are linked to PHC principles, thus providing healthcare services to vulnerable groups and promoting equity in healthcare access. This familiarises students with principles of PHC, as these principles were instilled during training and therefore promoted a PHC philosophy. This study revealed that a CBE programme promotes PHC philosophy.

\section{References}

1. Mtshali NG. Implementing community-based education in basic nursing education programs in South Africa Curationis 2009;32(1):25-32.

2. World Health Organization (WHO). Increasing the Relevance of Education for Health Professionals. Report of WHO Study Group on Problem Solving Education for Health Professionals. Geneva: WHO 1993.

3. WHO and United Nations Children's Fund ( UNICEF). International conference on primary healthcare. AlmaAta, USSR, 6 - 12 September 1978.

4. International Council of Nursing (ICN). Reducing the gap and improving the interface between education and service: A framework for analysis and solution generation. 2009. http://www.icn.ch/images/stories/documents/ publications/free_publications/reducing_the_rap.pdf (accessed 7 August 2012).

5. WHO. Community-based Education of Health Personnel. Report of a WHO Study Group. Geneva: WHO, 2012

6. Mekwa J. Transformation in nursing education. http://www.healthlink.org.za/uploads/files/chapter13_00.pdf. (accessed 27 May 2014).

(accessed 27 May 2014).

NG. Conceptualisation of knowledge construction in community service learnin programmes in nursing education. Curationis 2013;36(1):69-79.

8. Okayama O, Kajii E. Does community based education increase students' motivation to practice community health care? A cross sectional study. British Medical Council Medical Education 2011;11:19. [http://dx.doi.org doi:10.1186/1472-6920-11-19

9. Kaye DK, Mwanika A, Sewankambo S. Influence of the training experience of Makerere University medical and nursing graduates on willingness and competence to work in rural health facilties. Rural and Remote Health 2010;10(1):1-9.

10. Department of Education, South Africa. White Paper for the Transformation of the Health System in Sout Africa. Pretoria: Department of Education, 2013. http://www.healthlink.org.za/pphc/Phila/chap01-4.htm (accessed 27 January 2014)

11. Department of Health, South Africa. White Paper for the Transformation of the Health System in South Africa. Pretoria: Department of Health, 2012. http://www.info.gov.za/whitepapers/1997/health.htm (accessed 28 March 2012)

12. Gumbi RV, Muller ME. Health personnel education in South Africa. Health SA Gesondheid 1996;1(3):36-40.

13. Fichard AE, du Rand PP. Facilitators' perceptions of problem-based learning and community-based education. Health SA Gesondheid 2000;5(2):3-10.

14. Mtshali NG. Developing a community-based nursing education curriculum. In: Uys LR, Guele NS, eds Curriculum Development in Nursing Process and Innovation. New York: Routledge, 2005.

15. Sullivan CH. Educational innovations. Partnering with community agencies to provide nursing students with cultural awareness experiences and refugees health promotion access. Journal of Nursing Educatio 2009;48(9):519-522.

6. Lenz BK, Warner S. Global learning experiences during a domestic community health clinical. Nursing Education Perspectives 2011;32(1):26-29.

17. Bentley R, Ellison KJ. Impact of a service learning project on nursing students. Nursing Education Perspectives 2005;26(5):287-290.

18. Uys LR, Gwele NS. Curriculum Development in Nursing: Process and Innovation. New York: Routledge, 2005.

19. Australian Capital Territory. PHC strategy 2011 - 2014. 2010. http://www.health.act.gov.au/c/health?a=sendfile\& $\mathrm{ft}=\mathrm{p} \&$ fid $=1299734305 \&$ sid $($ accessed 18 April 2012)

20. Institute for Sustainable Communities. Community-based approach to education for sustainability. Developing a new generation for leaders through school-based programs linked to community issues. 2011. http://www.iscrt. org/who_we_are/publications/Education\%20for\%20Sustainability\%20Guidebook.pdf (accessed 20 November org/wh.

21. WHO and Health and Welfare Canada. Ottawa Charter for Health Promotion. An International Conference on Health Promotion, 17 - 21 November 1986, Ottawa, Canada. Geneva: WHO, 1986.

22. Reising DL, Shea RA, Allen PN, et al. Using service learning to develop health promotion and research skills in nursing students. International Journal of Nursing Education Scholarship 2008;5(1):1-18.

23. Eriskson GP. Community health nursing in a non-clinical setting: Service-learning outcomes of undergraduat students and clients. Nurse Educator 2004;29(2):54-57.

24. Lashley M. Nurse on a mission: A professional service learning experience with the inner-city homeless. Nursing Education Perspectives 2007;28(1):24-26.

25. Lazarus J, Erasmus M, Hendricks D, et al. Embedding community engagement in South African higher education. Education, Citizenships and Social Justice 2008;3(1):57-83.

26. Vogt MA, Chevez R, Schaffner B. Baccalaureate nursing student experiences at a camp for children with diabetes: The impact of a service learning model. Pediatric Nursing 2011;37(2):69-73.

27. Whelan I Spencer J Rooney K. A 'RIPPER' project: Advancing rural interprofessional health education at the Whian J, Spencer J, Rooney K. A 'RIPPER' project: Advancing rural in
University of Tasmania. Rural and Remote Health 2008;8(3):1017-1022.

University of Tasmania. Rural and Remote Health $2008,8(3): 1017-1022$. Education in South Africa. PhD thesis. Durban: University of KwaZulu-Natal, 2003.

29. Henry J. Meaning and practice in experiential learning. In: Weill SW, McGill I, eds. Making Sense of Experiential Learning: Diversity in Theory and Practice: Buckingham: SRHE and Open University Press, 1993.

30. Frenk J, Chen L, Bhutta ZA, et al. Education of health professionals for 21st century. Health professionals for new century: Tranforming education to strenghten health systems in an independent world. Lancet 2010;376:19231958. [http://dx.doi.org/10.1016/S0140-6736(10)61854-5]

31. WHO. Research for Universal Health Coverage: World Health Report. Geneva: WHO, 2013.

32. Keleher H, Parker R, Francis K. Preparing nurses for primary healthcare futures: How well do Australian nursing courses perform? Australian Journal of Primary Health 2010;6(3):211-216. 